\title{
Inflorescence and floral development of Carnarvonia (Proteaceae)
}

\author{
Andrew W. Douglas
}

\begin{abstract}
Douglas, Andrew W. (Royal Botanic Gardens, Melbourne, Birdwood Avenue, South Yarra, Victoria, 3141, Australia) 1996. Inflorescence and floral development of Carnarvonia (Proteaceae). Telopea 6(4): 749-774. Carnarvonia araliifolia is an endemic of north-east Queensland and the sole member of the subfamily Carnarvonioideae in Proteaceae. The inflorescence structure is atypical compared to the relatively simple racemiform architecture found in the other taxa of the family (including Grevilleoideae that has flower pairs). There is variability in numbers of flowers on a given axis, irregular branching of inflorescence axes, positions of flowers within an axillary module, numbers of flowers at a node on the principal axes, and the cauliflorous, axillary and/or terminal location of flowering regions on a branch. Carnarvonia has been hypothesized as having shared a common ancestor either with or within Grevilleoideae. Developmental evidence is examined to better define and elucidate the morphogenetic processes involved in the complex architecture of the inflorescence and flowers including the fundamental units of construction within a metameric conceptual framework. Likewise, the developmental evidence is used to examine the hypotheses of morphological derivation of the inflorescence as inferred from phylogenetic hypotheses. The inflorescence structure is interpreted as a paniculiform-raceme although terminal flowers are present on axillary inflorescence branches. There is variation within the developmental programme of the first three metamers of a subunit or axillary inflorescence branch that differs from the variation present in other Proteaceae and an inflorescence branch can vary in the number of flowers that develop. In the terminal flowers of a module, the first tepal is initiated in a position that follows the phyllotactic continuity of each subunit $(2 / 5)$, the first tepal being initiated in a predictable position based on the position of the preceding bract primordium. The carpel is initiated in a lateral position, closest to both the first initiated stamen and tepal, thus maintaining the phyllotactic continuity in the flower. The ontogenetic events involved in inflorescence development in Carnarvonia clarify its morphological organization and provide morphological evidence of the derivation of the inflorescence form from a single-flowered, perhaps racemiform, ancestor.
\end{abstract}

\section{Introduction}

Carnarvonia araliffolia F. Muell. (1867) is the sole member of the genus and is endemic to north-east Queensland (Hyland 1995). Originally, the genus was placed in Grevilleoideae (Engler 1889) based on the dehiscent follicle and winged seeds and in the tribe Macadamieae by Venkata Rao (1971) based on the regular flowers. Currently, the genus is placed in a subfamily of its own, Carnarvonioideae (Johnson \& Briggs 1975) on the basis of several unique characters like the loosely organized racemopaniculate inflorescence, fruit structure, 'partly digitate, partly pinnate and partly first-degree, partly second-degree division of the leaves' (Johnson \& Briggs 1975, p. 106-107), and several hypothetically independently derived characters or homoplasies such as the absence of hypogynous glands, and the the presence of two hemitropous ovules. Carnarvonia is also excluded from Grevilleoideae due to the fact that it lacks the grevilleoid flower pair condition (two flowers subtended by a common bract along the main axis; Johnson \& Briggs 1975). In Johnson \& Briggs (1975), Carnarvonia is hypothesized to be derived from a common ancestor of Grevilleoideae. 
The inflorescence of Carnarvonia is unlike the inflorescences in the rest of the family. The inflorescence architecture among taxa of most Proteaceae is essentially racemiform although there is a tremendous diversity of types or forms (e.g. frondose inflorescence, racemes, spikes, spadices, umbels and capitula). This includes Grevilleoideae that is

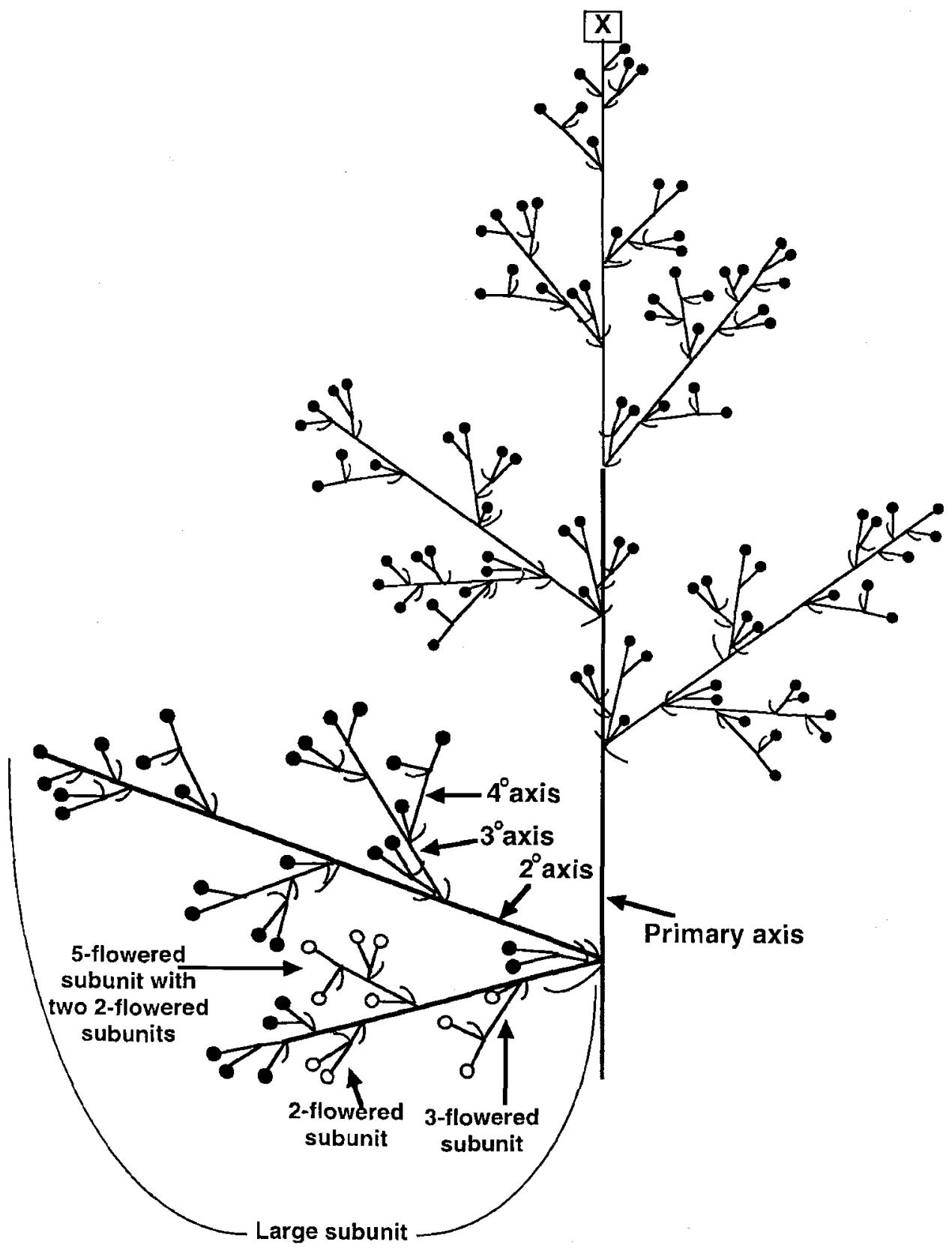

Fig. 1. Inflorescence diagram of Carnarvonia araliifolia. Main axis and branching axillary subunits. [In all figures except where noted, $\mathrm{T}=$ tepals, $\mathrm{S}=$ stamens, $\mathrm{mf}=$ median furrow, $\mathrm{tf}=$ transverse furrow, $\mathrm{G}=$ gynoecium; $\mathrm{O}=$ ovary, $\mathrm{i}=$ inner integument, $\mathrm{o}=$ outer integument; $\mathrm{a}=\alpha$-phyll, $\mathrm{b}=\beta$-phyll, $\mathrm{c}=\gamma$-phyll, $\mathrm{d}=\delta$-phyll, $\mathrm{x}=$ axis. $]$ 
characterized by the presence of flower pairs, each pair representing the products of first-order axillary meristems, analagous to a floral meristem on an inflorescence (Douglas \& Tucker 1996a). The inflorescence of Carnarvonia differs from other Proteaceae in that: it is paniculate in outline; it appears to have complex and irregular branching patterns; the smallest inflorescence branch units tend to be composed of two to four flowers, one of which is at the base of the inflorescence branch; inflorescences can develop from proleptic or sylleptic buds; inflorescence positions can be axillary on old or new growth or even represent the terminal portion of the shoot; and the flower, depending on its position on an inflorescence, can either have or lack a subtending bract (Fig. 1).

Implied in phylogenetic relationships are hypotheses of morphological changes of a homologous structure. Diverse forms of flowers and inflorescences are necessarily the products of differences in ontogenetic processes within each system. The hypothesized relationship of Carnarvonia as having shared a common ancestor with a taxon within Grevilleoideae (Engler 1889, Venkata Rao 1971) or as having a common ancestor with Grevilleoideae (Johnson \& Briggs 1975) implies a divergence of developmental patterns in inflorescence construction that is either derived from the basic 'grevilleoid raceme' and flower pair condition found within Grevilleoideae in the former or from a 'common-groundplan' with Grevilleoideae in the latter. Within a developmental comparative context, the specific processes that result in a particular or novel morphology can be assessed (Wardlaw 1952, Fink 1982). Additionally, a developmental morphological study necessarily increases the available information concerning a specific morphological form. This is an essential element in understanding evolutionary changes in form, particularly when taxa share common parts of a form but have different manifestations of the parts within the form. Thus, a comparative examination of the development of the inflorescence and flowers of Carnarvonia could yield insights into the common and divergent elements of construction involved in inflorescence architecture as well as provide criteria of homology for future phylogenetic analyses.

As part of an ongoing comparative developmental study of flower and inflorescence diversity in Proteaceae, this study describes the developmental events responsible for inflorescence and floral form in Carnarzonia and specifically aims to determine the basic developmental groundplan of the inflorescence using metameric concepts. Subsequently, these data will be used to examine the hypotheses related to the phylogenetic derivation of the Carnarvonia inflorescence and the grevilleoid flowerpairs and define the hypothetical changes that can or have occured in the diversification of inflorescences among Proteaceae.

\section{Materials and methods}

Specimens were obtained from multiple plants and populations from Mt Lewis, QLD. Additional material from cultivated wild plants was obtained from Yuruga Nursery, QLD. Floral and inflorescence material for developmental investigations was fixed in FAA (formalin - acetic acid - 50\% ethanol; 5:5:90) and subsequently rinsed and stored in $70 \%$ ethanol. Inflorescence and floral materials were microdissected in $100 \%$ ethanol under an Olympus SZH-10 photo-dissecting microscope with Schott KL-1500 fiber-optic illumination. Dissected materials were further dehydrated in an ethanol-acetone series. Due to the extreme density of hairs, even at the earliest stages of ontogeny, some materials were redissected in acetone, the trichomes being removed individually in many cases. After dissections, dehydration and critical point drying, the material was mounted on aluminum stubs using colloidal graphite and sputter coated with $\sim 100-400 \mathrm{~nm}$ of gold. In some cases, 
dried materials were further dissected with a sticky minuten pin to remove hairs that covered meristems. Prepared materials were viewed on a JEOL 840 scanning electron microscope and images were captured on Kodak T-Max 100, 120 mm roll film for later comparison. During dissections, some materials were photographed with a Nikon F2 on Kodak T-Max 100, $35 \mathrm{~mm}$ film, particularly when developing primordia had to be removed, to show the relationships of parts.

\section{Terminology}

Inflorescence terminology used is primarily the same as that in Briggs \& Johnson (1979), White (1979, 1984), Grimes (1992) and in some cases Weberling (1989). Some commonly used terms here include; a metamer to define the basic unit of an inflorescence that is composed of four distinct structures: 1) the internode proximal to the leaf homologue 2) the node and 3) a leaf homologue or bract or pherophyll, that subtends an 4) axillary meristem that can have differing developmental fates (White 1979, 1984). Principal axis refers to an axis that supports the metamers under discussion. Successive principal axes branch from the main axis (Fig. 1) and are called the primary, secondary, tertiary ... axes, each of which is a module the product of a single meristem or specifically a subunit (Grimes 1992) when referring to the sylleptic nature of the buds. Subunit is used here to describe the branches of the inflorescence and not the inflorescence strictly as inflorescences in Carnarvonia can develop from sylleptic or proleptic buds. It should also be noted that a flower is also a subunit although not referred to in that context here. To describe the structure and flowering pattern in Carnarvonia, the sequential and acropetal initiation of leaf homologue or bract primordia within a single module and subunit are assigned ascending greek letters $(\alpha, \beta, \gamma, \delta, \varepsilon \ldots)$. For example the first two leaf-homologueprimordia initiated from the flanks of an axillary meristem (i.e. prophylls) are termed the $\alpha$-phyll and the $\beta$-phyll.

\section{Observations}

\section{Mature organography}

Carnarvonia araliifolia is a rainforest canopy tree up to $30 \mathrm{~m}$ tall. The spirally arranged leaves can be simple, pinnate or palmately compound, and often covered with a dense indumentum when young. The inflorescence is a heterothetic racemiformpanicle (Fig. 1). In some specimens, flowering axes or modules proliferate on stems for upwards of 30 leaf nodes (approximately $60 \mathrm{~cm}$ ), and five season old axes. Inflorescences are variable and can be divided into two blastotelic types based on the position of the principal axes relative to the youngest shoot, the anauxotelic and auxotelic (Briggs \& Johnson, 1979). In most material examined, the inflorescence terminates the growth of the shoot (anauxotelic shoot systems) in which case there is a general serial transition of the leaves from compound to simple to bracteose (frondobracteose inflorescence), with inflorescence axes or subunits in each axil. New vegetative shoots tend to develop in the upper leaf axils, often being initiated from an auxiliary axillary meristem in an oblique transverse position next to the fallen inflorescence axis or persistent infructescent axis. Closer investigations reveal that the proleptic vegetative buds are initiated proximal to the inflorescence axes on the side facing the subtending leaf (Fig. 2) and are subsequently displaced to an oblique position. In some cases, shoot systems were auxotelic with axillary subunitary inflorescences either near the apex, or developing numerous nodes away from the 
shoot apex on older growth stems (in which case the leaf had usually fallen). In the case of auxotelic systems, vegetative growth continued beyond the axillary inflorescence regions in a monopodial fashion. On all anauxotelic systems, axillary inflorescences are also present on older growth.

The number of flowers per axis varies between 2 and 50. Compound branching (up to quaternary axes) of the inflorescence is greater in the terminal and near-terminal axillary inflorescences than the axillary inflorescences present on the older parts of the branch. Any branching axis of more than two flowers also has a flower or subunit inflorescence at the base in a bract axil ( $\alpha$-phyll) near the point of insertion. Flower numbers and secondary, tertiary and quaternary axis branching are greater in the basal metamers of each module and subunit, there being only one flower (Figs 3-4), two flowers (Fig. 5) or sometimes three flowers with one at the base of the small two-flowered principal axis (Fig. 6) towards the distal end of each inflorescence. At the base of insertion of axillary principal inflorescence axes, there is either a small inflorescence to one side of the larger inflorescence axis (Figs 1, 13) or in some cases

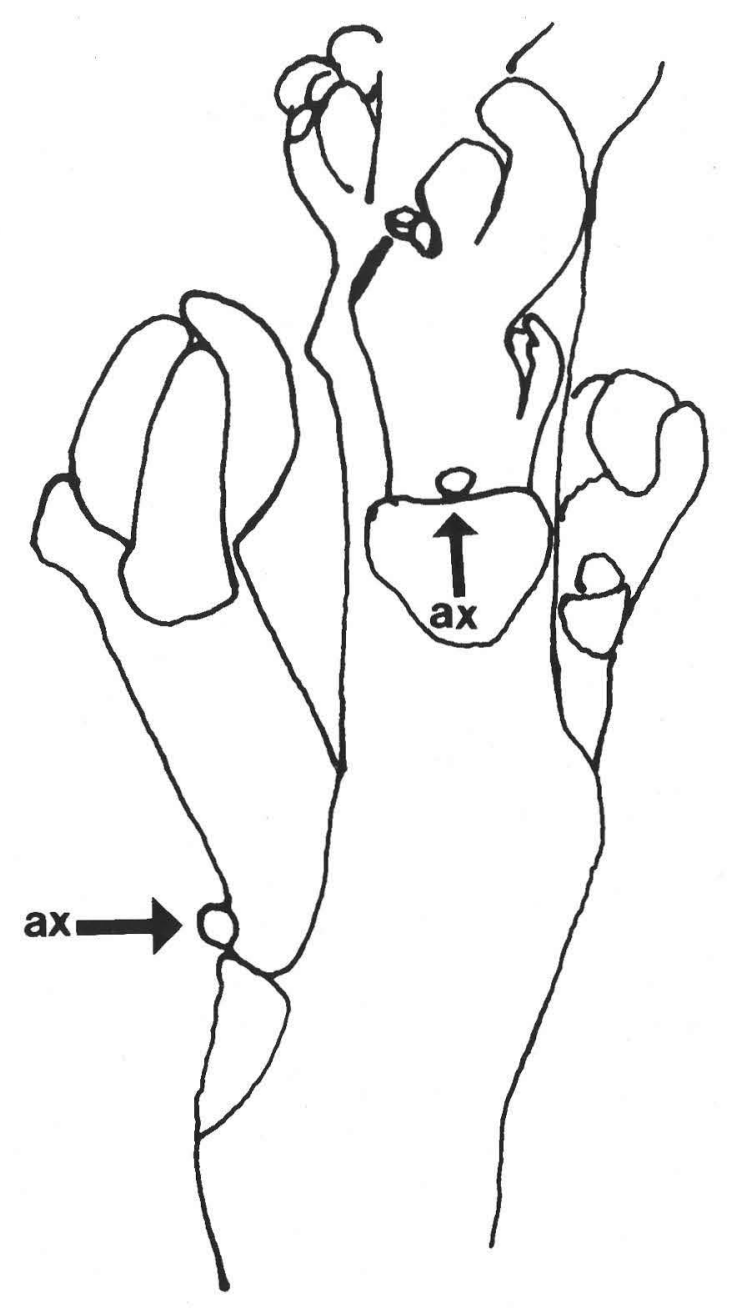

Fig. 2. Camera lucida drawing illustrating position of auxiliary axillary bud (ax) at base of a first order inflorescence branch. 

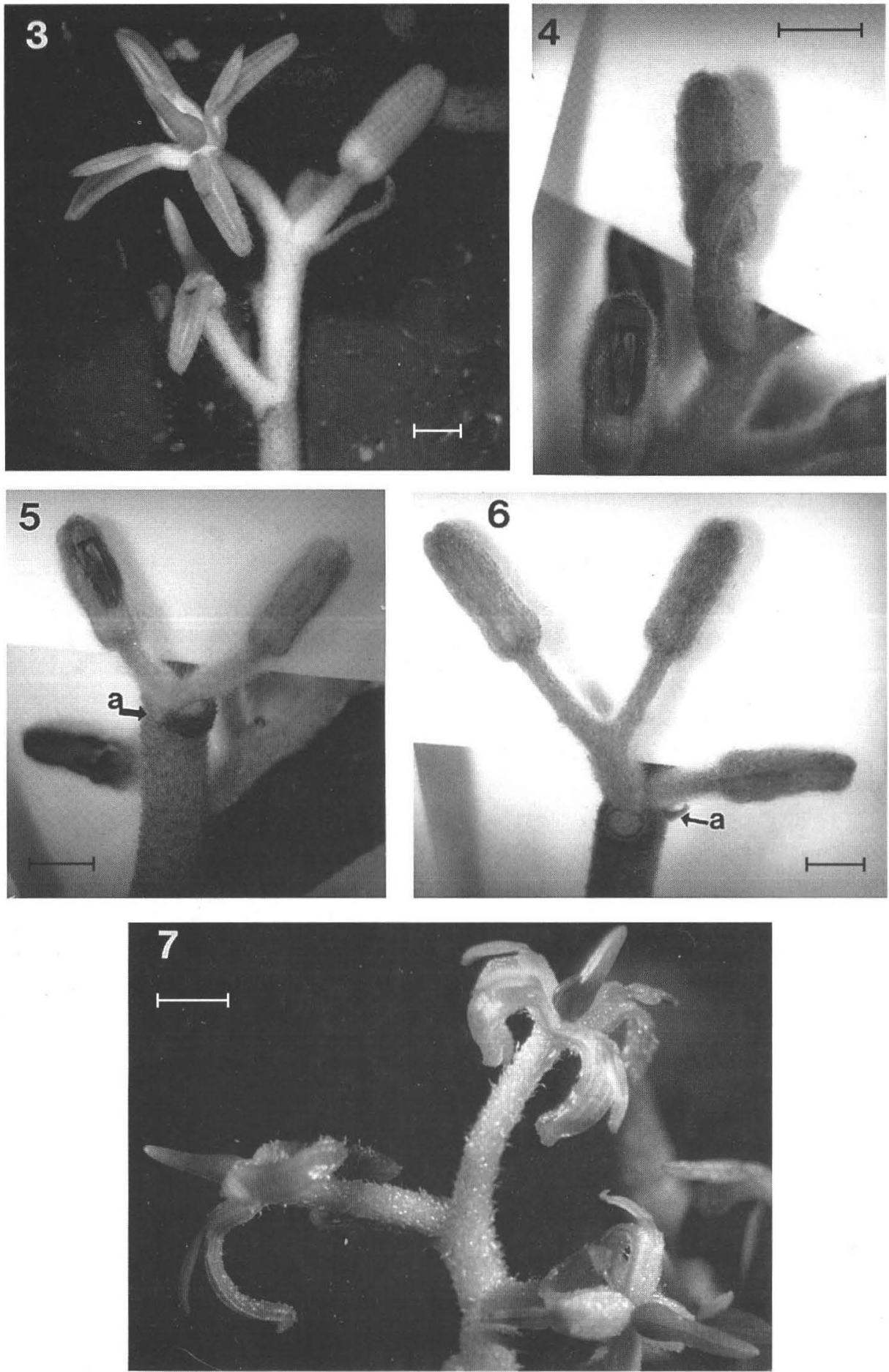

Figs 3-7. Flowers and buds towards terminus of subunit. Fig. 3. Terminal portion of subunit showing terminal flower and single flower in bract axil. Fig. 4. Close up of single flower bud in bract axil. Fig. 5. Close up of two-flowered subunit, the $\alpha$-phyll is small. Fig. 6. Close up of three flowered subunit. Fig. 7. Terminal flower and flower with no bract at anthesis. All scale bars $=2 \mathrm{~mm}$. 
a single flower (Fig. 1, 11). Most axillary subunits are anthotelic or determinate, having a terminal flower (Figs 3, 7). Other flowers along the axis are subtended by a bract (Fig. 4). In most material examined, the terminal portion of the primary or main axis appeared to senesce.

The pedicellate flowers are actinomorphic, the four free tepals reflexing equally at anthesis (Figs 3, 7, 12). Each epitepalous stamen filament is adnate to the lower half of a tepal. The distal half of each filament is free and stands slightly erect at anthesis. The filament is basifixed to the introrse anthers and there is a small connective protrusion distal to the microsporangia. In most cases, at anthesis, the pollen was contained within the anthers. In some cases, pollen was deposited around the distal end of the tapering style, proximal to the punctate and papillate stigma, although there are no morphological specializations of the style into a pollen-presenter. The mechanism of pollen adhesion around the style is unknown although pollen grains appeared to stick together at the apertures. The style broadens towards a stipitate ovary with a slightly lobed suture line. There are no hypogynous glands in the floral receptacle. Glandular trichomes line the claw of each tepal and fused filament and are composed of a basal tapered stalk and a globose end. An oily substance is exuded and the flowers have a strong 'Passionfruit fragrance' (P. Weston, pers. com.).

\section{Inflorescence topography/ontogeny}

Early ontogenetic stages of inflorescence and floral development are concealed by precocious trichome development. The anauxotelic portion of the inflorescence maintains a 2:5 phyllotaxis (Fig. 14) as is found in the vegetative axis. Transitory stages between vegetative and inflorescence apices were not examined.

At the base of each lateral inflorescence axis or subunit composed of more than three flowers, just above the point of axis insertion in the leaf axil (Fig. 11), there is a single bract ( $\alpha$-phyll) normal to the median sagittal plane of the axis (Figs 8-10, 13). Within each $\alpha$-phyll axil there can be a flower, a small inflorescence or a senesced meristem. Developmental studies demonstrate that the $\alpha$-phyll of the first metamer is persistent. The $\alpha$-phyll can be positioned on the left (Fig. 17) or right side (Fig. 18) of the axis in relation to the subtending leaf primordium depending on the inflorescence. In some two-flowered and single flowered systems, there is no evidence of an $\alpha$-phyll. The initiation of primordia and development of inflorescences in Carnarvonia is relatively similar for each axillary meristem or subunit. Below is a descriptive ontogeny of the inflorescence relative to the enlargement and development of subunits with deviations cited as appropriate.

An axillary meristem (subunit meristem) is initiated within a leaf- or leaf-homologueaxil from the primary axis. The meristem enlarges and becomes slightly oblate although relatively flat (Figs 14-16). The first primordium or $\alpha$-phyll, is initiated from the lower flank of the meristem in a transverse position relative to the leaf (Fig. 17). On different inflorescences the $\alpha$-phyll varies between the left (Fig. 17) or right side (Fig. 18). Trichomes differentiate at the tip of the enlarging $\alpha$-phyll primordium (Fig. 18-19). The second primordium, the $\beta$-phyll, is initiated from the opposite side of the meristem, approximately 180 degrees from the $\alpha$-phyll (Figs 19-20). During the initiation of the $\beta$-phyll, there is slight elongation/differentiation of the internode between the $\alpha$ - and $\beta$-phyll (mesopodium) as evidenced by the restrictive trichome development and the lateral displacement of the $\alpha$-phyll from the subunit-axis (Figs 21-22). As the subunit inflorescence apex enlarges and prior to and during the initiation of the $\gamma$-phyll, a meristem can enlarge in the axil of the $\alpha$-phyll (Figs 22, 23). There is variation in extent of axillary meristem enlargement in the $\alpha$-phyll (compare the similar developmental stages in Figs 22 and 23). Within the axils of $\alpha$-phylls in the subunits 

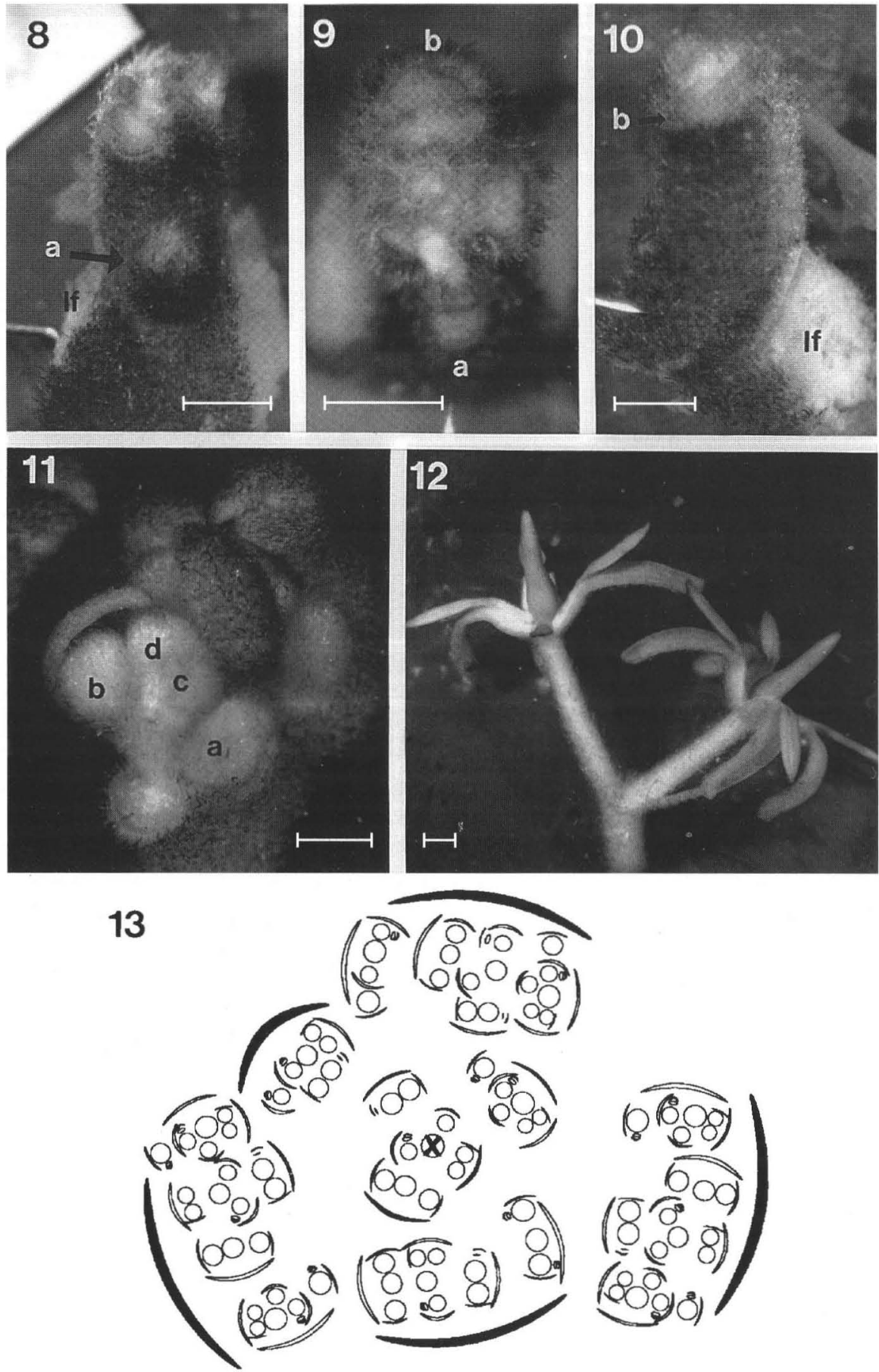

Figs 8-10. Partially dissected first order subunit showing position of $\alpha$-phyll node relative to subunit and main axis. Fig. 8. $\alpha$-phyll side of subunit. Fig. 9. Polar view of same subunit. Fig. 10. $\beta$-phyll side of subunit. If=removed leaf side of main axis. Fig. 11. Partially dissected subunit showing flower in $\alpha$-phyll node, the flower in the $\beta$-phyll node and the two flower buds at the top. Fig. 12. Terminal flower and single flowered system at top of subunit. Fig. 13. Theoretical inflorescence diagram of main axis $(x)$ and some modular axes. All scale bars $=1 \mathrm{~mm}$. 

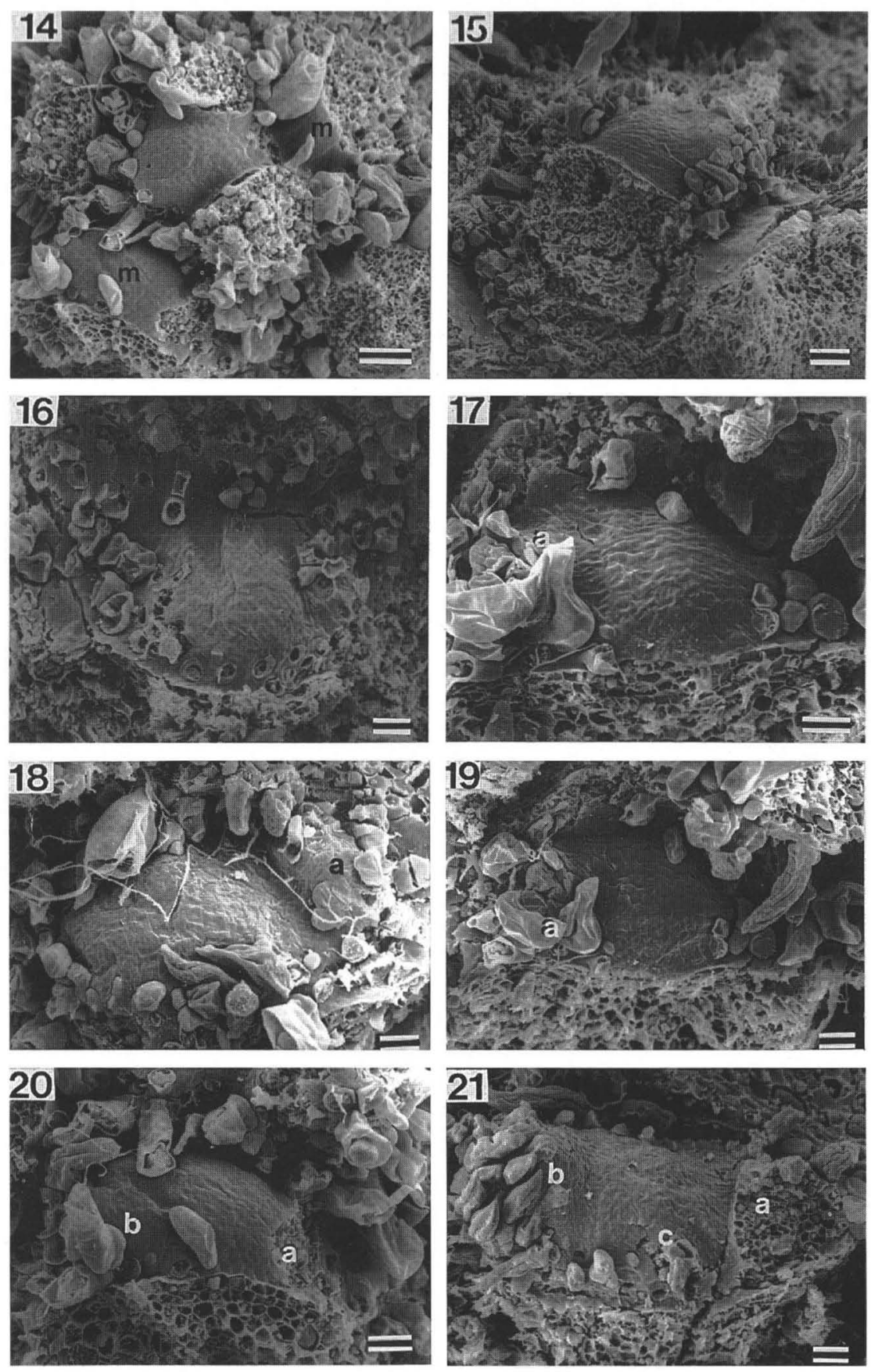

Figs 14-21. Fig. 14. Polar view of anauxotelic axis illustrating $2 / 5$ phyllotaxis, the bracts are dissected away. Meristems $(\mathrm{m})$ are enlarging in some of the more proximal bract axils. Fig. 15. Side view of anauxotelic axis with axillary meristems developing in bract axils (bracts removed). Fig. 16. Polar view of enlarging tertiary subunit axillary meristem. Fig. 17. Later developmental stage of axillary meristem illustrating the initiation of the $\alpha$-phyll. Fig. 18. Axillary subunit with $\alpha-$ phyll and the initiation of the $\beta$-phyll. Fig. 19. Enlarging $\alpha$-phyll on subunit and early expansion of subunit meristem. Fig. 20. Initiation of $\beta$-phyll (b) from meristem. Fig. 21. Initiation of $\gamma$-phyll (c) on leaf side close to $\alpha$-phyll site. Scale bars: $14-15=50 \mu \mathrm{m} ; 16-21=25 \mu \mathrm{m}$. 
closer to the top of the main axis or one of the subunit axes, the meristem in the axil of the $\alpha$-phyll tends to be larger and higher (Fig. 23) than in the $\alpha$-phylls lower on an axis (Fig. 22), possibly indicating the transition to a floral meristem (see below).

The $\gamma$-phyll is initiated approximately $150^{\circ}-165^{\circ}$ from the $\beta$-phyll from the flank of the meristem on the subtending leaf side of the axis (Figs 21, 23, 25). Bract initiation continues from the inflorescence axis, the $\delta$-phyll being initiated approximately $135^{\circ}-140^{\circ}$ from the preceding primordium (Fig. 24). The anthotaxis approaches a $2: 5$ spiral (Fig. 25) with the initiation of successive bract primordia. Axillary meristems develop in the axil of each bract. From each axillary meristem, the pattern of bract initiation can repeat the pattern described above (a \& b in Fig, 26, E-K in Fig. 66).

There are variations in the development of axillary meristems among the more distal metamers of an inflorescence axis that involve floral organogenesis and morphogenesis. The deviations are found primarily among the one- and two-flowered subunits. The results of these architecturally significant patterns are discussed in more detail below.

\section{Flower organogenesis}

There was variation in the position of flowers relative to the subtending bract on the principal axis as well as in the enlargement of the axillary meristem. In addition, there is variation in patterns of organogenesis in the axillary and terminal flowers.

A floral meristem enlarges within a bract axil. If there are no other primordia (e.g. $\alpha$-phyll) initiated, the floral meristem becomes tangentially oblate and more highly convex (Figs 27, 28) than an inflorescence meristem (Figs 16, 17). There is variation in the shape of the meristem, some being more tangentially oblate (Fig. 29) than others (Fig. 27). The first tepal initiated is in a transverse position relative to the floral bract followed by the initiation of the second tepal in the opposite transverse position (Fig. 27).

In other cases, when there are $\alpha$ - or $\beta$-phylls present, tepal initiation appears to follow the established phyllotactic spiral of the subunit. When there is an $\alpha$-phyll only, the first tepal is initiated in the opposite transverse site relative to the $\alpha$-phyll, positionally similar to where a $\beta$-phyll would be initiated (Fig. 30). In such cases, the second tepal is approximately opposite the first tepal. The third tepal is initiatiated in a site $90^{\circ}$ from the second tepal (Fig. 30). Similarly, in subunits with an $\alpha$ - and $\beta$-phyll, the first tepal is initiated in the $\gamma$-site, thus following the established phyllotactic pattern of the subunit.

Sequential stamen initation is difficult to assess although the pattern appears similar to the patterns of tepal initiation. After initiation of the tepals, the floral meristem expands (Fig. 31). In flowers that develop from the remaining modular axis with an $\alpha$-phyll and no $\beta$-phyll (the terminal flowers of a subunit), the first two stamens are initiated in sites opposite the first two initiated tepals (Fig. 32) and the third stamen is initiated $90^{\circ}$ from the second and first stamen (Fig. 33). In other terminal flowers, the pattern of stamen initiation appears to be unidirectional from the subsequent site of the last bract primordium (unidirectional from the $\beta$-site in Figs. 36, 37).

In cases where there is no $\alpha$-phyll, the first two stamens initiated are in transverse sites opposite the tepals found in the approximate $\alpha$ - and $\beta$-sites (Figs. 34, 35). The sagittal stamens are initiated after the lateral stamens (Fig. 35). Each stamen is directly opposite a tepal (tepals removed in Fig. 36). In many cases, the sequential initiation of stamens is not determinable due to differential enlargement of the floral meristem.

The stamen primordia appear to enlarge at different rates, presumably in a similar pattern to the specific inititiation sequence of the differently positioned flowers. 

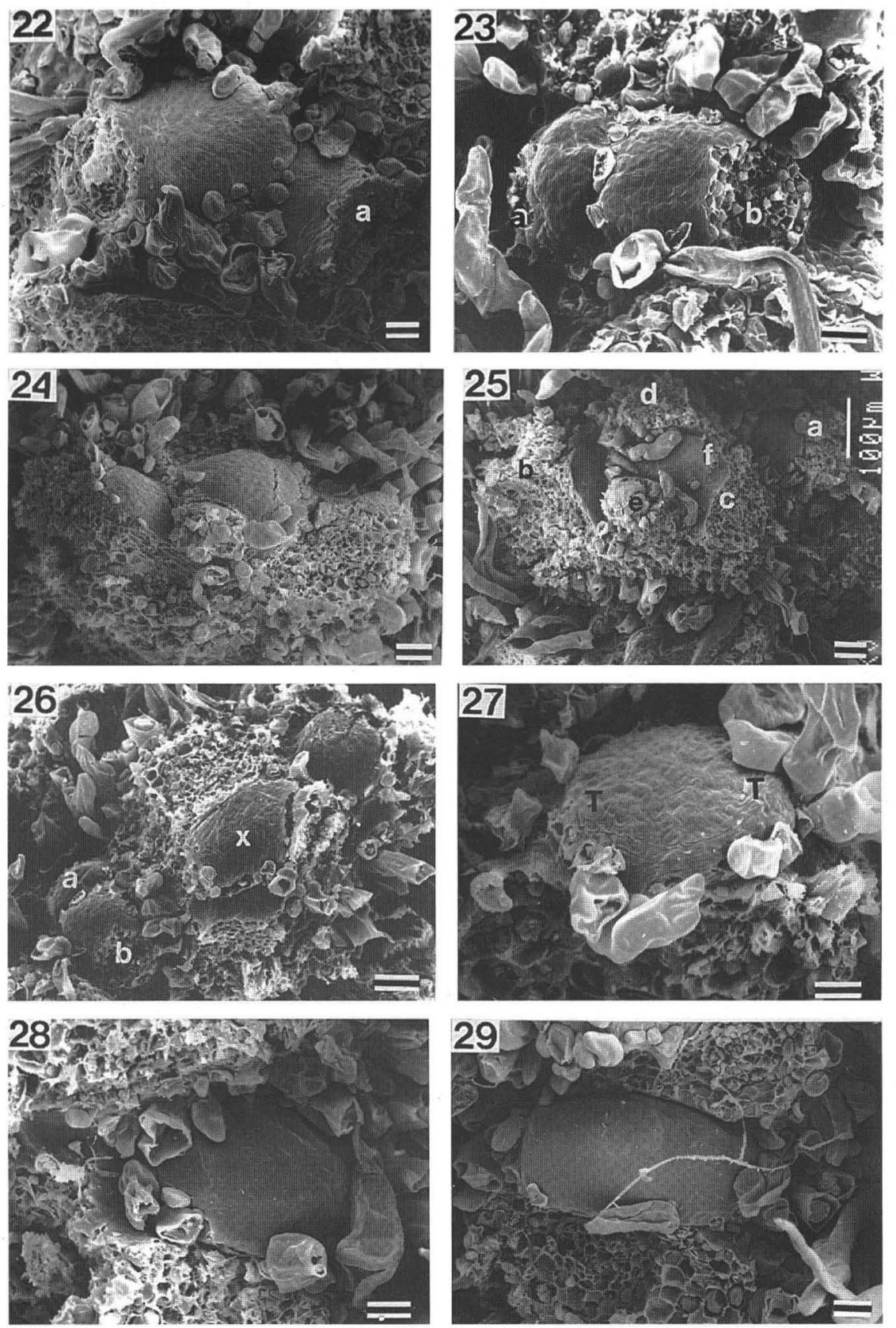

Figs 22-29. Fig. 22. Polar view of subunit axis showing the initiation of the $\gamma$-phyll (c) and a meristem enlarging in the axil of the $\alpha$-phyll. Fig. 23. Polar view of subunit axis showing initiation of $\gamma$-phyll on leaf side of axis and the enlarging meristem in the axil of the $\alpha$-phyll. Fig. 24. Axillary subunit whowing the flat meristem enlarging in the axil of the $\alpha$-phyll. Fig. 25. Polar view of developing axillary subunit showing the sequential initiation of bracts (a-f) and the 2/5 spiral after the third (c) bract or $\gamma$-phyll. Fig. 26. Enlargement of meristems in bract axils. The secondary meristem/subunit axis in the $\beta$-phyll has initiated an $\alpha$ - and $\beta$-phyll $(a, b)$ : (the $\alpha$-phyll of the principal subunit axis is not visible). Fig. 27. Polar view of enlarging floral meristem. Fig. 28. Oblique view of enlarging floral meristem. Fig. 29. Polar view of transversely oblate enlarging floral meristem near top of subunit axis. Scale bars: $22-23,27-29=25 \mu \mathrm{m} ; 24-26=50 \mu \mathrm{m}$. 

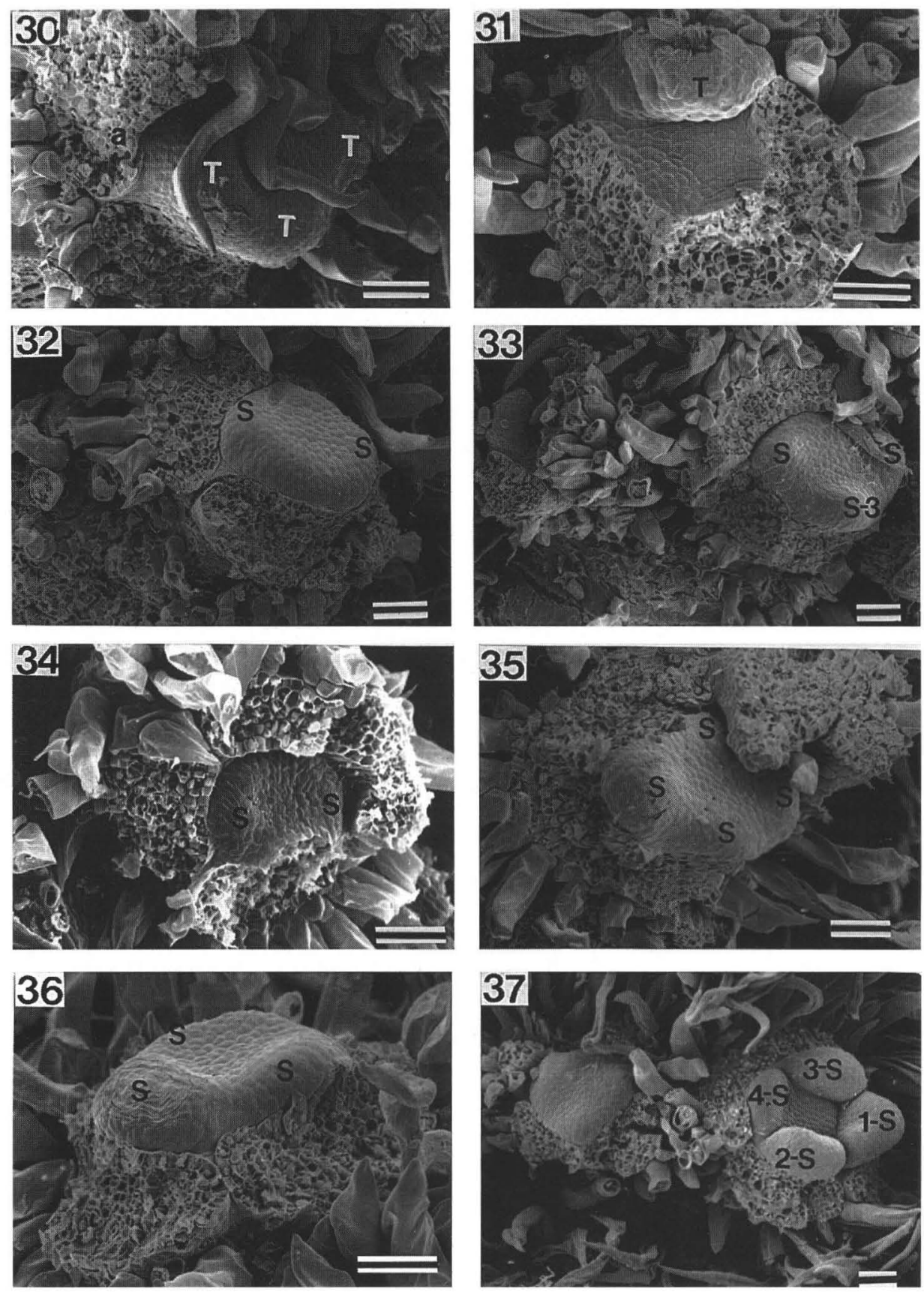

Figs 30-37. Fig. 30. Lateral view of tepal initiation in a floral meristem with an $\alpha$-phyll. Fig. 31. Polar view of floral meristem after tepal initiation. Fig. 32. Polar view of first two stamens initiating from a terminal floral meristem. Fig. 33. Oblique view of terminal floral meristem, the third stamen (S-3) has been initiated in a site perpendicular to the first two-stamen primordia. Fig. 34. Initiation of first two stamen primordia in transverse positions relative to the subtending bract. Fig. 35. Initiation of the two stamen primordia in sagittal positions on single-flowered metamer. Fig. 36. Side view of floral meristem showing unidirectional initiation of stamen primordia from a terminal flower of a multi-nodate subunit. Fig. 37. Differential enlargement of stamen primordia on a terminal flower of a subunit following the sequence of initiation (numbered). Scale bars: $30-37=50 \mu \mathrm{m}$. 

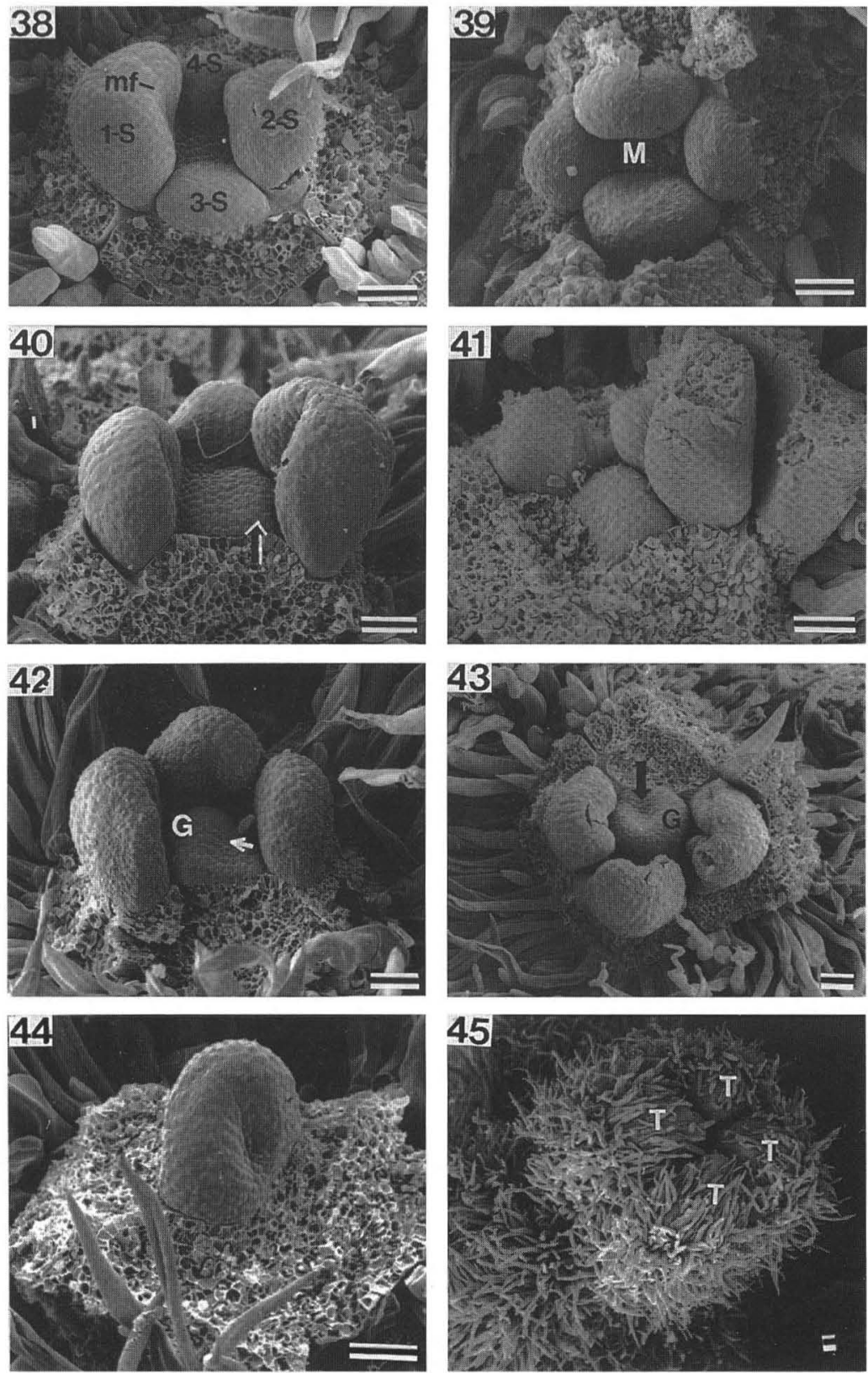

Figs 38-45. Fig. 38. Oblique view from removed bract showing differential enlargement of stamen primordia on a single flowered unit that follows the pattern of initiation (numbered). The median furrow $(\mathrm{mf})$ has begun on the first initiated stamen primordium. Fig. 39. Polar view of floral meristem (M) after stamen initiation. Fig. 40. Side view of enlarging floral meristem/early carpel (arrow) with one stamen primordium removed illustrating the growth on the side of the largest stamen primordium. Fig. 41. Later stage of enlarging floral meristem/carpel primordium. Fig. 42. Side view of carpel primordium, the cleft beginning to form (arrow). Fig. 43. Polar view of carpel primordium with cleft (arrow). Fig. 44. Oblique side view of carpel primordium, all stamens and tepals removed. Fig. 45. Oblique view of incomplete valvate tepal aestivation; only two tepal tips converge and come into contact over the other floral organs. The other two tepals fit into the corners formed by the contacting tepals. Scale bars: $38-44=50 \mu \mathrm{m} ; 45=100 \mu \mathrm{m}$. 
In the terminal flowers on a subunit, stamen enlargement appears unidirectional; the first stamen primordium is larger than the transverse stamen primordia that in turn are larger than the stamen primordium directly opposite the largest stamen primordium (Figs 36, 37). In the single flowers that lack an $\alpha$-phyll, the first stamen primordium, in a transverse site, becomes larger than the other three stamen primordia (Figs $38-40$ ). The second stamen primordium, approximately $180^{\circ}$ from the first stamen primordium, is the next largest (Figs. 38, 40). After stamen initiation, the remaining floral meristem is flattish and bilaterally shaped in outline (Fig. 39).

Carpel initiation begins as one portion of the remaining floral meristem begins to enlarge, usually the side closest to the largest stamen (Fig. 40). The higher part is the dorsal side of the carpel primordium (Figs 41,42). At a carpel height of approximately $85 \mu \mathrm{m}$, the cleft becomes apparent on the ventral side (Figs 43, 44). The early development of the carpel is epeltate or conduplicate, with no apparent cross zone.

\section{Floral morphogenesis}

After initiation, the floral organs begin to differentiate. The tepal margins become appressed or valvate and two opposing tepal tips come into contact with one another over the other floral organs; the other two opposing tepal tips do not come into contact with one another but fit into the corners formed by the other tepals (Fig. 45 - incomplete valvate aestivation). In bud, the tepal tips are slightly incurved and elongate cells differentiate at the tip (Fig. 46). Zonal growth beneath and between each tepal and its opposing stamen results in the epitepalous condition when the tepals are approximately $400 \mu \mathrm{m}$ high (Fig. 46). Trichomes develop in the lower half or claw of each tepal (Fig. 47), each trichome the product of a single cell. The trichomes differentiate and become globose at the distal-most portion before anthesis (Figs. 48, 49). A pair of bump-like processes develop on each tepal, a single process on each side of the tepal distal to the point of tepal-stamen adnation (arrow in Fig. 49). Additional bump-like processes develop distal to the first pair of bumps. At anthesis, there can be three or four bumps per row (Fig. 50).

The stamen primordia enlarge and differentiate at different rates. The median furrow becomes visible when the stamen primordia are $90 \mu \mathrm{m}$ high (Figs 38, 40). The transverse furrows form at a stamen height of approximately $125 \mu \mathrm{m}$ (Figs 51, 52). The relative position of the transverse furrow is introrse compared to the differentiating connective (Fig. 52). A small connective appendage distal to the enlarging microsporangia becomes

Figs 46-54. (right) Fig. 46. Two dissected away tepals and stamens showing that zonal growth has begun between and beneath each tepal/stamen filament (f) complex. A small connective appendage is present on each stamen (cn). Fig. 47. Close up of dorsal surface of tepal and point of tepal/stamen adnation showing the initiation and enlargement of the trichomes. Fig. 48. Close up of dorsal surface of tepal and point of tepal/stamen adnation showing the enlargement of the trichomes over the adnate filament. Fig. 49. Close up of dorsal surface of tepal and point of tepal/stamen adnation before anthesis, showing partially free filament and the mature globose ended trichomes. A bumplike process (arrow) has developed distal to the point of tepal/stamen adnation. Fig. 50. Close up of dorsal surface of tepal and point of tepal/stamen adnation at anthesis showing three processes on each side of the tepal above the point of tepal/stamen adnation. Fig. 51. Polar view of young flower, tepals removed, showing the development of the microsporangia via the presence of the transverse furrows. Fig. 52. Polar view of enlarging flower, one stamen removed showing the differentiation of the stamens and the small connective appendage (cn). Fig 53. Oblique side view of flower with stamen and tepal removed showing the enlarging semi-tubular carpel primordium (G) with the cleft extending to the base and the differentiating stamens. Fig. 54. Removed young stamen/tepal complex showing the distinct fused filament (fi) and the initiation of trichomes. Scale bars: 46, 49-50, $53-54=100 \mu \mathrm{m} ; 47-48,51-52=50 \mu \mathrm{m}$. 

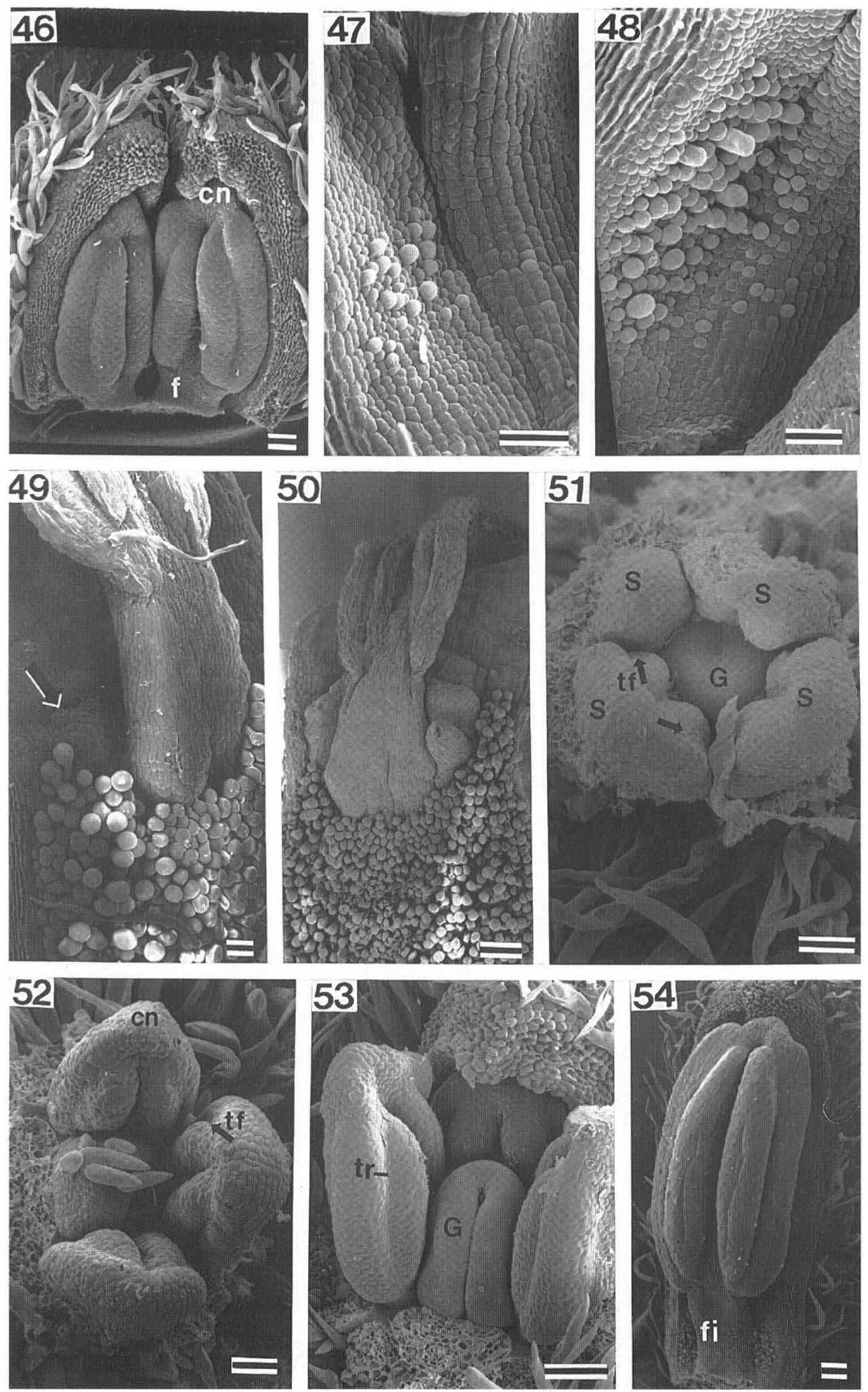

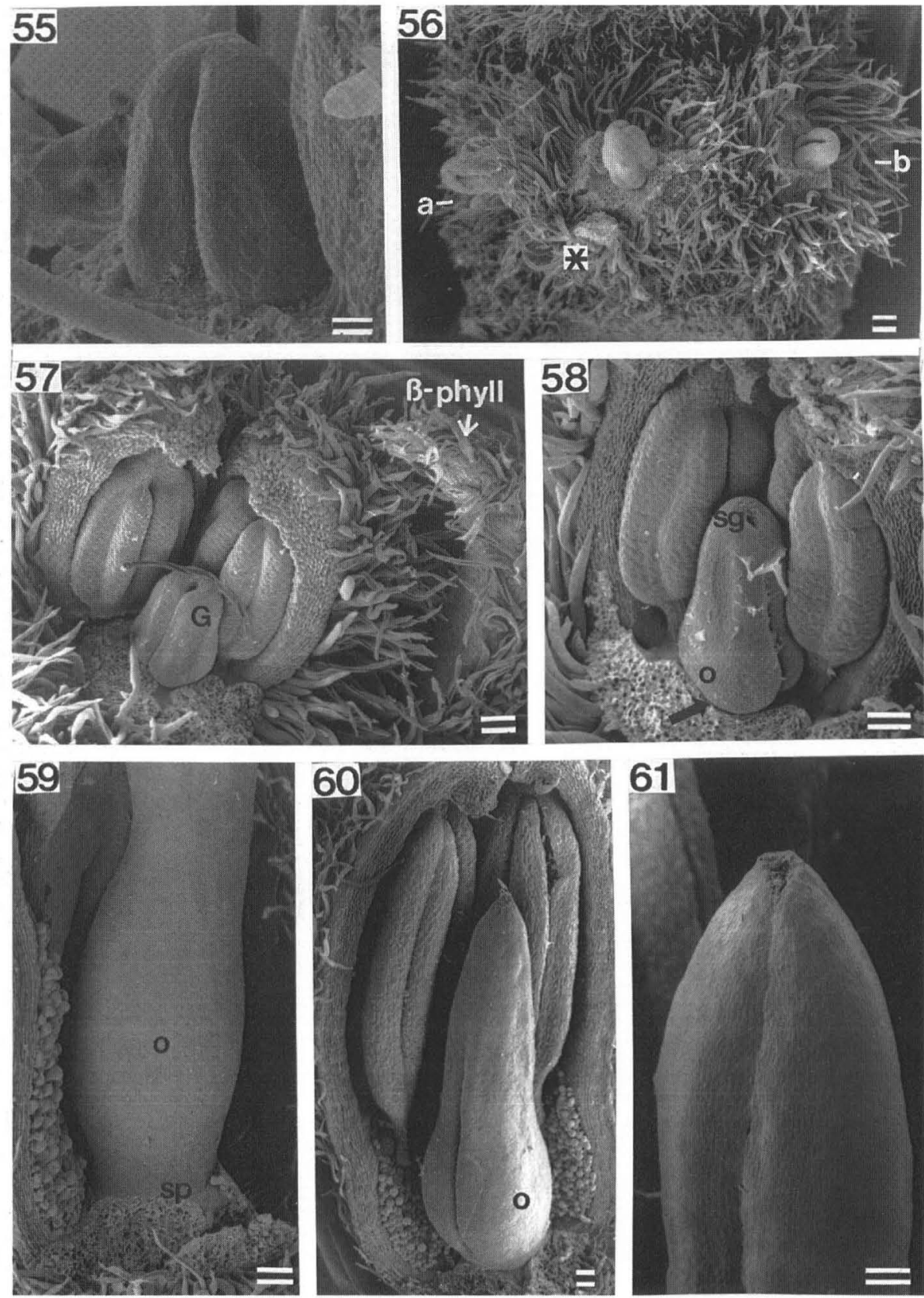

Figs 55-61. Fig. 55. Oblique ventral view of carpel primordium, the cleft extending to the base. Fig. 56. Polar view of partially dissected three flowered subunit. The orientation of the carpel is such that the dorsal side of each carpel is facing the subtending bract in the $\alpha$-phyll (a) and $\beta$-phyll (b) and the dorsal side of the carpel in the terminal flower is facing the site where the first tepal is presumed to have been initiated $(*)$. Fig. 57. Oblique polar view of partially dissected flower showing the enlarging carpel $(\mathrm{G})$ and the broadening at the base. Fig. 58. Oblique side view of differentiating carpel with papillae beginning to form at the distal end or stigma (sg) and the broadening of the ovary (o). At the base of the ovary, a stipe is beginning to enlarge (arrow). Fig. 59. Side view of ovary (o) and stipe (sp) of preanthesis flower. Fig. 60. Side view of partially dissected immature flower showing the differentiated carpel. Fig. 61 . The punctate stigma. Scale bars: $55=25 \mu \mathrm{m} ; 56-61=100 \mu \mathrm{m}$. 
apparent as the transverse furrow forms (Figs 52-54). The filament is relatively short before zonal growth beneath and between each tepal-stamen complex begins (Fig. 46). The distal portion of the filament remains free (Fig. 50). The young anthers are approximately equal in size by the time zonal growth commences (Fig. 53). The adaxial side of the filament remains distinct on the fused tepal-filament interface (Fig. 54). Trichomes develop on the tepal-filament interface after trichome initiation on the adaxial side of each tepal (Figs 48,54). The trichomes continue to differentiate, obscuring the epitepalous condition of the filament (Fig. 50). At anthesis, the anthers dehisce via longitudinal lines along the transverse furrow (Figs 60, 65).

The carpel primordium enlarges and the cleft reaches the base (epeltate - Fig. 55). The orientation of the carpels on the two- and three-flowered subunits appear variable. However, as is illustrated in Fig. 56, a three-flowered subunit, the carpel in the axil of the $\alpha$-phyll is aligned with the cleft facing $180^{\circ}$ away from the subtending $\alpha$-phyll; the carpel cleft in the flower in the axil of the $\beta$-phyll faces away from the $\beta$-phyll;
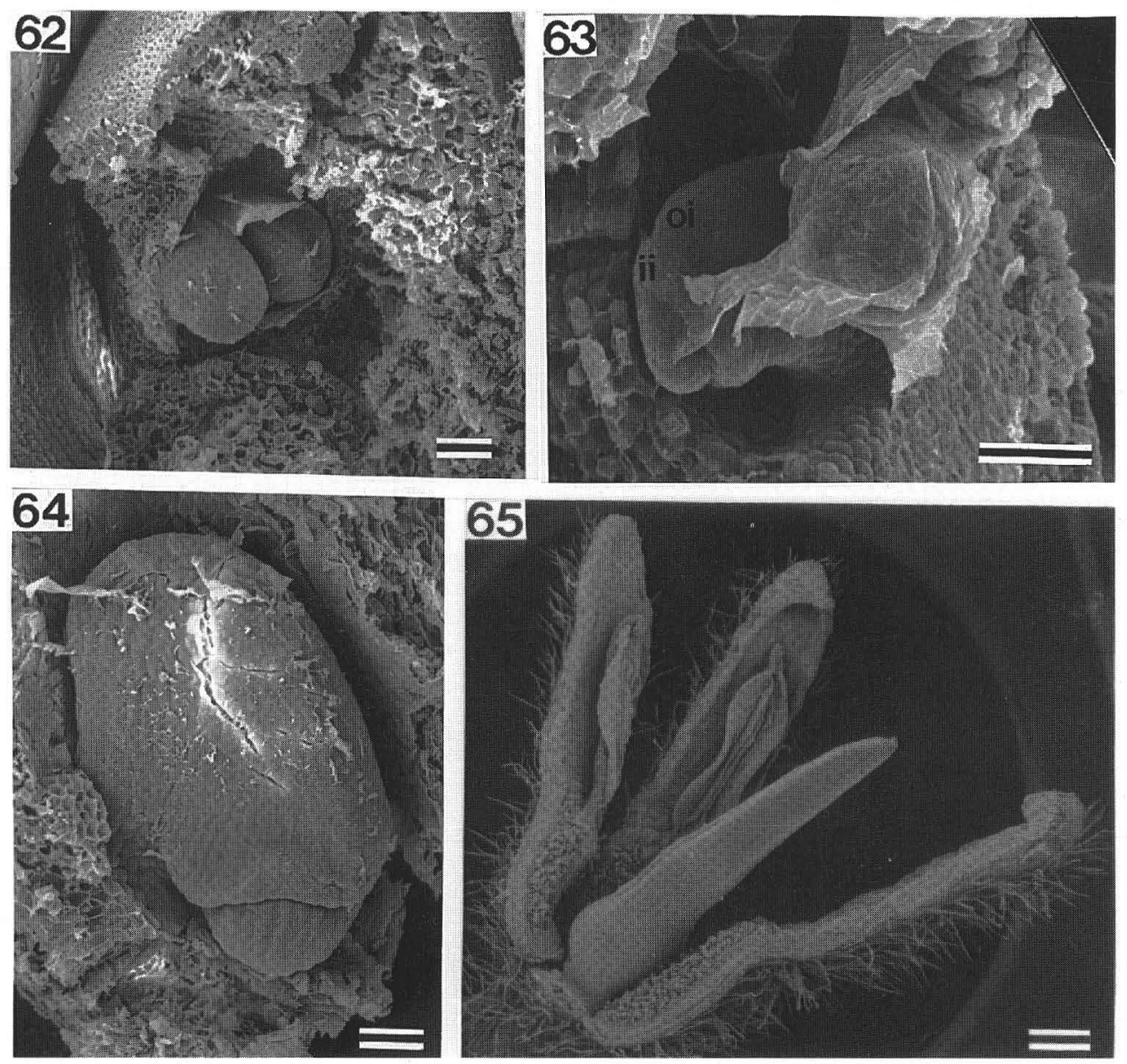

Figs 62-65. Fig. 62. Dissected ovary showing the initiation of two ovule primordia from lateral positions within the loculus. Fig. 63. Dissected ovary showing the initiation and development of the outer and inner integuments (oi and ii respectively). The ovules are beginning to arch downwards into the loculus. Fig. 64. Mature ovule is hemitropous. Fig. 65. Flower at anthesis showing the lateral dehiscene of the antherss and the erect carpel. Scale bars: $62-64=50 \mu \mathrm{m} ; 65=500 \mu \mathrm{m}$. 
and the carpel cleft in the third, terminal flower, with no subtending bract, is facing in a position directly opposite where one would have expected to find the $\gamma$-phyll ${ }^{*}$ in Fig. 56), the dorsal side of the carpel next to the largest stamen that is next to the first initiated tepal. In virtually all cases examined, the carpel cleft was facing away from the subtending bract or the site where a bract would be predicted (42 other singleflowered, two-flowered and three-flowered subunits were investigated).

The top of the carpel appears tubular or porate at a carpel height of $\sim 250 \mu \mathrm{m}$ (Fig. 57). Enlargement of the base of the carpel represents the early morphogenesis of the ovary (Fig. 58). At a similar stage, the differentiation of the stigma occurs with the differentiation of papillae around the inner surface of the distal pore (Fig. 58). An invagination beneath the enlarging ovary represents the early development of a stipe (arrow in Fig. 58) at a carpel height of approximately $500 \mu \mathrm{m}$. The stipe continues to elongate (Fig. 59). The suture line is persistent (Figs 60-61). Papillae continue to differentiate on the porate stigmatic area (Fig. 61) and after anthesis when the stigma becomes receptive, the papillae are extended (Fig. 65).

Two ovule primordia are initiated in lateral positions on the placental margins at about the same time as stipe elongation (Fig. 62). The outer integument is initiated after the inner integument and the young ovules begin to curve downwards into the loculus (Fig. 63) attaining a hemitropous condition at anthesis (Fig. 64).

\section{Discussion}

\section{Inflorescence and floral form}

The mature inflorescence structure is dramatically different from that in other members of Proteaceae that are basically racemiform or elaborations of a raceme. The inflorescence in taxa of Grevilleoideae appears more complex on account of the presence of two flowers or flower pairs in the axil of common bracts along principal axes. Nevertheless, the inflorescence structure in Grevilleoideae is racemiform, the flower pairs being the product of a developmental modification of first order axillary meristems or subunits (Douglas \& Tucker 1996a). The inflorescence of Carnarvonia is paniculiform in outline, with a decrease in modular branching as one ascends the inflorescence, and has terminal flowers on most modular axes, without dichasial units or cymes. In Carnarvonia, the inflorescence is a panicle as defined by Rickett (1955): 'a loosely branched inflorescence of which the ultimate units may be of various types'. However, Briggs \& Johnson (1979) called for a more strict definition, and restricted the term panicle to anthotelic inflorescences in accord with the usage of Troll and Weberling. In the material examined, there is no terminal flower on the main axis. In this case, the inflorescence of Carnarvonia is most similar to a pleiobotryum in accordance with Troll (1964). Mueller (1867) described the inflorescence as 'racemo-paniculate' although a paniculiform raceme would better define the basic condition of the inflorescence as an elaboration of a raceme.

Developmentally, the diverse inflorescence architecture of Carnarvonia is somewhat plastic. There are several different developmental pathways of the axillary meristem from the point of origin and subsequent development. The simplest model to explain the elaboration of the inflorescence is the timing of commitment and differentiation events of the axillary meristems and their products within a subunit (Fig. 66). Within the axil of a bract from the main axis or a subunit, an axillary meristem enlarges (Fig. 66A). As the basic unit of construction, an axillary meristem will produce the first two organs in transverse positions in relation to the subtending leaf or the 
$\alpha$ and $\beta$ prophylls (in dicots). Depending on the position of the axillary meristem in relation to other axillary branches on the main or subunit axis, the meristem can become a flower (Fig. $66 \mathrm{~A}^{1}$; distal parts of subunits or main axis) or an $\alpha$-phyll can be initiated (Fig. 66B). If an $\alpha$-phyll is initiated, a meristem develops in its axis and the meristem can either senesce (Fig. $66 \mathrm{~B}^{1}$ ) or can enlarge, giving rise to a floral or subunit meristem (Fig. 66C $C^{1}-\mathrm{G}$ ). These processes, starting with an axillary meristem, can be repeated with each successive metamer (arrows to 'A' - Figs 66C-G').

The complexity of the inflorescence is not due to the number or arrangement of the parts but rather to the degree of reiteration of the developmental pattern at different hierarchical levels within the inflorescence. In this sense, the elaboration of the inflorescence is the product of differential proliferation of a shared developmental pathway within each subunit. The same developmental pathway found in the primary axis is present in the secondary, tertiary and higher axes resulting in a hierarchical arrangement of complexity. The fate of each axillary meristem is thus the product of the competence and extent to which the meristem will repeat the patterns expressed at lower hierarchies. In addition, the number of flowers on any one subunit appears to be related to the presence or absence of the $\alpha$-phyll.

Towards the end of a subunit axis or the primary axis, one, two or three flowers will develop, usually all but one of the flowers are in a bract axil. In the case of three flowers, one flower is the product of the axillary meristem in the $\alpha$-phyll and two are the product of the subunit axis, one generally developing in the axil of the $\beta$-phyll. In the case of two flowers, they can be either, 1) the product of the axillary meristem in the $\alpha$-phyll and the transformation of the remaining modular meristem or 2) both can be the product of the modular meristem with little or no evidence of an $\alpha$-phyll. In the one-flowered systems, the flower appeared to be the sole product of the axillary meristem in the bract axil, although in some, an $\alpha$-phyll was initiated.

In most cases, the initiation of the first floral organ followed the previously established phyllotactic pattern of the subunit $(2 / 5)$ although there is a shift in divergence angle with successive floral primordia to a $1 / 4$ pattern. In the single flowered systems with a subtending bract only, the sequential initiation of tepals is similar to most other Proteaceae with the frontal or transverse tepal pair arising first. Weberling (1989; Eichler 1875/1878) termed this pattern as 'eprophyllate aestivation'; that is, the first two floral organs to develop are positioned as if they were prophylls (two in dicots, one in monocots; Weberling 1989). A developmental presumption in eprophyllate aestivation patterns is that the position at initiation of the first two primordia of a flower is influenced by the position of the preceding organ(s), or that the sequential initiation of an organ from a meristem is influenced by the position of the preceding organ (Hofmeister in Weberling 1989; Eichler 1875-8; termed phyllotactic continuity within a flower by Posluszny 1993). In the case of single flowers in bract axils of Carnarvonia and most other Proteaceae, the organ subtending the flower appears to influence the subsequent initiation of the first floral organs; therefore a more appropriate term would be eprophyllate initiation (Douglas 1994; Douglas \& Tucker 1996a, b, in press). In taxa with a single flower borne in a leaf axil, the first two organs to be initiated are generally in lateral positions, analogous to prophylls on a vegetative meristem (e.g. Drimys lanceolata Tucker 1959; Pseudowintera traversii Sampson \& Kaplan 1970; Sanguinaria Lehmann \& Sattler 1993). Similarly, the initiation of the first two floral organs in lateral positions is found in taxa with flowers that develop in bract axils on blastotelic inflorescences: (e.g. Papaverales Sattler 1973, Karrer 1991; some flowers of Scrophulariaceae Weber 1973; Armstrong \& Douglas 1989; Liquidambar styraciflua Wisniewski \& Bogle 1982; Potamogetonaceae Posluszny 1993; also see Douglas and Tucker 1996a for additional examples). 


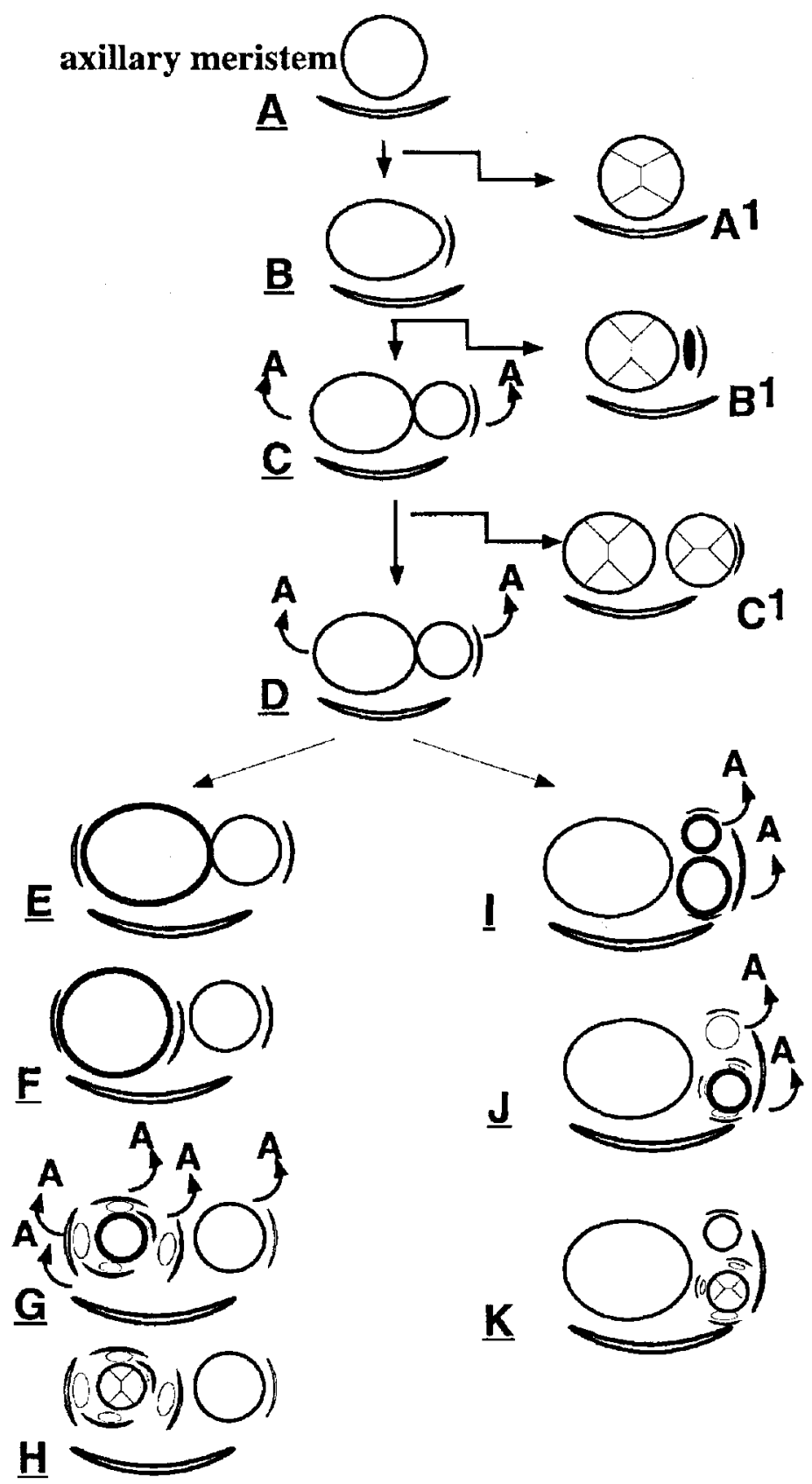

Fig. 66. Summary ontogenetic flow diagram of modular construction from the origin of an axillary meristem (A) and the options possible at each successive developmental stage. After initiation of an axillary meristem, each axillary meristem returns to point $A$. See text for additional interpretation. 
A contrasting order of initiation is seen in taxa that have bracteoles (prophyllate aestivation sensu Weberling, 1989). The first floral organ (or first two floral organs in some four-merous taxa) is initiated on the side furthest from the axis and in a plane perpendicular to the transverse or frontal plane in numerous Leguminosae (Tucker 1984, 1987a, 1987b, 1992, Tucker \& Stirton 1991); Juglandaceae, Myricaceae, Fagaceae (MacDonald 1971; Sattler 1973; Abbe 1974); Arecaceae (Uhl 1988), and Onagraceae (Sattler 1973).

In Carnarvonia, the sequence of initiation of the tepals, particularly the terminal flowers of a determinate subunit, appear to be directly influenced by the preexisting organs of a subunit. In the cases where there is no observable subtending bract to the terminal flower, the first tepal is initiated in a site continuous with the established phyllotactic sequence of the subunit. Phyllotactically continuous patterns of perianth initiation (phyllotactic continuity) have been found in flowers of anthotelic axes of some Ranunculaceae (Wydler 1872), Linaceae (Bravais \& Bravais 1837) and Alismataceae (Charlton 1973, 1981).

In Camarvonia, the carpel is initiated and positioned in a site that is phyllotactically continuous with the preceding primordia of the flower. In most proteaceous taxa, after stamen initiation, the remaining floral apex enlarges throughout and is fully converted to a carpel primordium (Douglas 1994; Douglas \& Tucker 1996b, in press). In Carnarvonia, the carpel primordium is initiated towards one side, the dorsal side of the carpel being next to the first tepal and stamen that were initiated. A longstanding controversy in flower evolution is whether the single carpel is a terminal or lateral structure (Newman 1936a, b; Thompson 1936 a, b; Brooks 1940; Tucker \& Gifford 1966). Considering the well-supported hypothesis that the carpel is a leaf homologue (Goethe 1790; although see Meeuse 1963, 1965, 1966 for an alternate opinion), one would expect to find vestigial evidence of the floral residuum in single-carpellate taxa, particularly if the carpel is a lateral organ (Newman 1936a,b). Apical residuum in unicarpellate flowers is rare and is not present in Carnarvonia. The phyllotactic continuity of the flower organs through the carpel stage can be considered a general developmental condition where the sites of sequential initiation of primordia from the meristem perseveres. Deviations from a pattern of phyllotactic continuity can be considered a developmentally derived condition.

\section{Architectural/physiological constraints}

The mature inflorescence architecture is loosely constrained in Carnarvonia, although from a developmental perspective at the level of the axillary meristem and its products, the inflorescence architecture is conserved. In most plant systems, it has been hypothesized that there are canalised ontogenetic events that maintain a taxon specific morphology or architecture (conservation of organization, Waddington 1962). It has also been hypothesized that in an ontogenetic pathway, alterations in early ontogeny result in the macroevolutionary differences among taxa. On the other hand, changes that occur later in an ontogeny tend to be significant to microevolutionary patterns of morphological differences among taxa (Tucker 1984, 1988). Unfortunately, most of the studies of developmental canalization and ontogenetic constraint models focus on features in the flowers and not the inflorescences.

Conservation of organization is apparent in inflorescence architectures among taxa, particularly when one considers the fact that an inflorescence is the reproductive equivalent of a branching system as proposed by Linnaeus (1751; Rickett 1944) and as a branching system, it is made up of metamers that combine to define a module or subunit (White 1979, 1984). Barlow (1989) defines a hierarchical basis of morphological organization, each hierarchy of which combines its individual elements to make up 
the next hierarchical level (cells $>$ meristems $>$ metamers $>$ modules $>$ organ system $>$ plant). Metamers are composed of four elements (node, internode, leaf and axillary meristem) and the sum of metamers from a single meristem make up a module. Considering that selection can differently effect individual organs or elements within organs (Guerrant 1988), it is plausible to hypothesize that variation and selection as well as developmental and phylogenetic canalisation can occur at different levels within the metamer or even the subunit in inflorescences. In Carnarvonia it can be hypothesized that there is a level of canalisation of a subunit starting with the first three metamers. The first metamer does not have an elongate internode, the second metamer does have an elongate internode and the third bract primordium, based on developmental evidence, is positionally out of line with the predicted phyllotactic position of the bract primordium $\left(160^{\circ}\right.$ as opposed to $\left.100^{\circ}-120^{\circ}\right)$. The deviation in position of the third primordium of the third metamer is most likely a result of a timing (heterochronic) and/or spatial (heterotopic) shift between the initiation of the first and third primordium or possibly as a result of precoccious differentiation of the internode of the second metamer.

Diversity of inflorescence architecture is the product of developmental shifts in timing and positions of various ontogenetic processes starting with the products and patterns of apical meristems (Grimes 1992). It has been hypothesized that physiological mechanisms inherent in a plant's architecture are affected at the level of axillary and apical meristems (White 1979, 1984; Grimes 1992) and that the duration and extent of growth of the meristem (that produces metamers or plant-units) is taxonomically constrained as well as ecologically influenced; conservation of form among taxa is the result. Under such a metameric concept, the inflorescence architecture of a plant is a product of conserved genetic and physiological mechanisms inherent in the plant or more specifically, shoot, as well as the product of historically imposed phylogenetic constraints (Cheverud et al. 1983, Janson 1992).

There is a progressive acropetal reduction of flower numbers and branching patterns along the inflorescence. The variation of branching and/or flower numbers at levels along the inflorescence could be a function of the ontogenetic contingency of axillary meristems or in other words, the developmental fate of a primordium depends upon where and when it is produced within the architecture of the organism and what events have preceded it during ontogeny (Diggle 1995). In such a case, there is a shift in physiological and morphological products of the axillary meristems along the developing principal axes. An ontogenetic contingency as outlined above would necessarily involve a physiological or possibly an epigenetic feedback system (Sundberg et al. 1995). The variation in products of axillary meristems could be a result of resource availability or be based on a physiological cue to commit the axillary meristems to flower production given their position and size at a specific time. Both have been hypothesized in various plant systems. Mullins (1980) demonstrated that the inception of inflorescence meristems in Vitis can be induced with the presence of specific plant growth substances at specific times in development. In Carnarvonia, evidence for a physiological cue comes from the fact that subunits and inflorescences tend to develop synchronously on an individual and that there is a distinct difference in the shape of a meristem that will give rise to 'inflorescence' subunits/metamers (flat, less concave) compared to a meristem that will become a flower (higher and more concave). Physiological hypotheses have been proposed for the amplification of row numbers in Maize and putative relatives (Sundberg \& Doebley 1990; Sundberg et al. 1995) and in the origin of the flower pairs in the proteaceous subfamily Grevilleoideae (Douglas 1994, Douglas \& Tucker 1996a). 


\section{Phylogenetic affinities}

The inflorescence architectures of different proteaceous taxa are valuable in defining taxonomic groups and specific architectures appear to be generically conserved in most cases. Proteaceous taxa with compound racemiform inflorescences plus variable flower numbers on ascending branches include Symphionema and Conospermum of Proteoideae. The developmental events leading to the inflorescence of Carnarvonia are valuable in understanding the evolution of reproductive structures in Proteaceae.

It can be hypothesized that the inflorescence structure in Carnarvonia is a novel state derived from the single-flowered condition found in the inflorescences of Proteoideae, Persoonioideae and Sphalmioideae compared to the two-flowered condition in Grevilleoideae. In all single-flowered systems, the flower develops as a product of the axillary meristem and no prophylls are present (Douglas 1994, unpub.; Douglas \& Tucker 1996a,b, in press). In fact, the first two tepals to be initiated are in transverse positions analagous to the $\alpha$ - and $\beta$-phyll sites. In Grevilleoideae, an axillary meristem enlarges in the axil of a common bract on the main axis. The meristem becomes transversely oblate and two floral bracts are initiated, one on each side. Within the axil of each of the floral bracts, a floral meristem will enlarge (the pattern of tepal initiation being identical to flowers of the other subfamilies) and the apical residuum of the short-shoot axis differentiates and senesces. There is no differential elongation of subtending internodes between the two flowers and likewise there are no terminal flowers in Grevilleoideae examined (Douglas 1994; Douglas \& Tucker, 1996a). It has been hypothesized that the flower-pairs in Grevilleoideae are either the product of reduction of secondary inflorescence branches to two flowers or the product of a constrained amplification of first-order axillary meristems to two flowers (Douglas \& Tucker 1996a).

Carnarvonia is the sister taxon to Grevilleoideae in Johnson \& Briggs's (1975) phylogeny. Carnarvonia was excluded from Grevilleoideae based on several features including the fact that the inflorescence of Carnarvonia does not have the flower-pair condition (Johnson \& Briggs 1975). As the sister-taxon to Grevilleoideae, there is an implied morphological transformation hypothesis of reduction to the flower-pair condition from a Carnarvonia-like inflorescence architecture and/or the diversification of inflorescence architecture from a similar developmental program in each lineage, one branch leading to Carnarvonia the other to Grevilleoideae. To attain the flowerpair condition from a Carnarvonia inflorescence there could be a change in developmental timing and growth between the initiation of the first two metamers of a subunit and a loss of the ability of the terminal portion of a subunit meristem to develop into a flower. The fact that in Carnarvonia there is differential enlargement of axes, and the presence of a terminal flower on each subunit, the first tepal of which is initiated in a site consistent with the phyllotactic pattern of the subunit before moving to a $1 / 4$ pattern suggests that the inflorescence form is possibly derived from a single-flowered system as has been hypothesized for Grevilleoideae (Johnson \& Briggs 1975; Douglas \& Tucker 1996a).

Venkata Rao (1971) and Engler (1889) classified Carnarvonia as a member of Grevilleoideae. Under this hypothesis, the Carnarvonia inflorescence would be derived from amplification of the flower paired condition. Developmentally, this transformation could result from an amplification of the primary axillary meristems, perhaps a proliferation of the axillary meristem via a delay in the commitment of flowering and the production of terminal flowers on each subunit, the latter of which is unique in the family. Morphologically, the hypothesis that Carnarvonia is derived from within Grevilleoideae seems unlikely given the synorganised floral 
systems in the latter. All Grevilleoideae (except Neorites) have a morphological and anatomical modification of the style-end that is termed a pollen-presenter because it holds and displays the dehisced pollen from the anthers. There are several developmental and morphological features in the flowers associated with the pollenpresentation systems in Grevilleoideae including lobes around the upper portion of the filament that clutch the basal portion of the pollen-presenter, differential cell enlargement and growth in the style and a highly synorganized tepal-stamen-carpel enlargement process (Douglas, unpub.). It is evident from developmental studies of other grevilleoid taxa that the pollen-presentation systems have become increasingly elaborate and involve numerous facets of a flower and its development, thus the synorganization has increased. Given the interdependence of floral organs developmentally, structurally and functionally in highly synorganized flowers (Endress 1990, 1994) it seems unlikely that a pollen-presenter and all of the associated floral features could be lost. Although loss of a pollen-presenter system is possible, it seems dubious based on the various developmental processes involved in other parts of the flower among Grevilleoideae. A phylogenetic analysis of the family is necessary however before Venkata Rao's (1971) hypothesis can be entirely dismissed. There are two other possibilities concerning the origin of the Carnarvonia inflorescence; one being the amplification of a single flowered system as found in non-grevilleoid taxa via the delay of commitment to flowering of axillary meristems or that the Carnarvonia inflorescence is a plesiomorphic condition for Proteaceae derived from a common ancestor that had an anthotelic or blastotelic panicle.

Developmental studies here illustrate that there are several unique features to the genus not found in other Proteaceae (as well as those characters cited in Johnson \& Briggs 1975), hence providing little support for allying the taxon with any one proteaceous group. In a phylogenetic analysis of the family (Douglas in prep), Carnarvonia is in a basal position within the family or as a basal branch leading to Persoonioideae/Proteoideae, but the branch length of Carnarvonia is invariably long relative to other branches and hence there is a bit of topological plasticity. Until a thorough phylogenetic analysis has been undertaken, the combination of apparently autapomorphic features and plesiomorphic and homoplastic features (sensu Johnson \& Briggs 1975) within Carnarvonia are interpreted here to imply a long time isolation from other Proteaceae and perhaps the opinion that it occupies a basal position relative to extant taxa is justifiable.

\section{Acknowledgements}

I am grateful to the Pacific-Dunlop Post-doctoral Fellowship at the Royal Botanic Gardens, Melbourne for supporting this research. Scanning electron microscopy was carried out at the School of Botany, University of Melbourne. I am also indebted to Jim Grimes, Barbara Briggs, Peter Weston, Alistair Hay and Peter Wilson for critically evaluating, and offering valuable insights into earlier copies of this manuscript.

\section{References}

Abbe, E.C. (1974) Flowers and inflorescences of the 'Amentiferae'. Bot. Rev. 40: 160-261.

Armstrong, J.E. \& Douglas, A.W. (1989) The ontogenetic basis for corolla aestivation in Scrophulariaceae. Bull. Torr. Bot. 116(4): 378-389.

Barlow, P.W. (1989) Meristems, metamers and modules and the development of shoot and root systems. Bot. J. Linn. Soc. 100: 255-279.

Bravais, L. \& Bravais, A. (1837) Essai sur la disposition symmétrique des inflorescences. Ann. Sci. Nat., ser. 2, Bot. 7. 
Briggs, B.G. \& Johnson, L.A.S. (1979) Evolution in the Myrtaceae - evidence from inflorescence structure. Proc. Linn. Soc. New South Wales 102: 157-256.

Brooks, R.M. (1940) Comparative histogenesis of vegetative and floral apices in Amygdalus communis, with special reference to the carpel. Hilgardia 13: 249-299.

Charlton, W.A. 1973. Studies in the Alismataceae. II. Inflorescences of Alismataceae. Can. J. Bot. 51: 775-789.

Charlton, W.A. (1981) Features of the inflorescence of Triglochin maritima. Can. J. Bot. 59: 2108-2115.

Cheverud, J.M., Rutledge, J. \& Atchley, W.R. (1983) Quantitative genetics of development: genetic correlations among age specific trait values and the evolution of ontogeny. Evolution 37: 895-905.

Diggle, P.K. (1994) The expresssion of andromonoecy in Solanum hirtum (Solanaceae): phenotypic plasticity and ontogenetic contingency. Amer. J. Bot. 81: 1354-1362.

Douglas, A.W. (1994) Evolutionary patterns in Proteaceae based on comparative floral and inflorescence ontogenies. (Ph.D. thesis, Louisiana State University).

Douglas, A.W. \& Tucker, S.C. (1996a) Inflorescence ontogeny and floral organogenesis in Grevilleoideae (Proteaceae), with emphasis on the nature of the flower pairs. Int. J. Plant Sci. 157:

Douglas, A.W. \& Tucker, S.C. (1996b) The developmental basis of diverse carpel orientations in Grevilleoideae (Proteaceae). Int. J .Plant.Sci. 157:

Douglas, A.W. \& Tucker, S.C. (in press) Comparative floral ontogenies among Persoonioideae including Bellendena (Proteaceae). Amer. J. Bot.

Eichler, (1875/1878) Blüthendiagramme II. (Otto Keoeltz: Eppenhain).

Endress, P.K. (1990) Patterns of floral construction in ontogeny and phylogeny. Biol. J. Linn. Soc. 39: 153-175.

Endress, P.K. (1994) Diversity and Evolutionary Biology of Tropical Flowers (Cambridge University Press: Cambridge).

Engler, A. (1889) Proteaceae. Pp. 119-156 in A. Engler \& K. Prantl (eds.), Die Natürlichen Pflanzenfamilien: III, 1 (Englemann: Leipzig).

Fink, W.L. (1982) The conceptual relationship between ontogeny and phylogeny. Paleobiology 8: 254-264.

Goethe, J.W. (1790) Versuch der Metamorphose der Pflanzen zu erklären (Gotha).

Grimes, J. (1992) Metamerism, heterochrony, and inflorescence morphology of the Pithecellobiumcomplex (Leguminosae: Mimosoideae: Ingeae). Brittonia 44: 140-159.

Guerrant Jr., E.O. (1988) Heterochrony in plants. Pp. 111-133 in M.L. McKinney (ed.), Heterochrony in Evolution. (Plenum Press: New York).

Hyland, B.P.M. (1995) Carnarvonia. Pp. 343-345 in A.E. Orchard (ed.), Flora of Australia, vol. 16 (CSIRO: Melbourne).

Janson, C.H. (1992) Evolutionary constraints. Evolution 46: 136-158.

Johnson, L.A.S. \& Briggs, B.G. (1975) On the Proteaceae - the evolution and classification of a southern family. J. Linn. Soc., Bot. 70: 83-182.

Karrer, A.B. (1991) Blütentwicklung und systematische Stellung der Papaveraceae und Capparaceae (Ph.D. thesis, University of Zurich).

Lehmann, N.L. \& Sattler, R. (1993) Homeosis in floral development of Sanguinaria canadensis and S. canadensis 'multiplex' (Papaveraceae). Amer. J. Bot. 80: 1323-1335.

Linnaeus C. (1751) Philosophica Botanica.

MacDonald, A.D. (1971) Floral development in the 'Amentiferae' (Ph.D. thesis, McGill University).

Meeuse, A.D.J. (1963) From ovule to ovary: a contribution to the phylogeny of the megasporangium. Acta Biotheor. 15: 127-182.

Meeuse, A.D.J. (1965) Angiosperms - past and present. Advancing Frontiers of Plant Sciences, 11. (Institute for the Advancement of Science and Culture: New Delhi).

Meeuse, A.D.J. (1966) Fundamentals of Phytomorphology (Ronald Press: New York).

Mueller, F. (1867) Fragmenta 6: 80

Mullins, M.G. (1980) Regulation of flowering in the grapevine. Pp. 323-330 in F. Skoog (ed.), Plant Growth Substances (Springer: Berlin).

Newman, I.V. (1936a) Ontogeny of the angiospermic carpel. Nature 137: 70-71.

Newman, I.V. (1936b) Studies in the Australia Acacias. VI. The meristematic activity of the floral apex of Acacia longifolia and A. suaveolens as a histogenetic study of the ontogeny of the carpel. Proc. Linn. Soc. New South Wales 61: 56-88.

Posluszny, U. (1993) Evolution of the helobial flower. Aquatic Botany 44: 303-324.

Rickett, H. W. (1944) The classification of inflorescences. Bot. Rev. 10: 187-231. 
Rickett, H. W. (1955) Materials for a dictionary of botanical terms - III. Inflorescences. Bull. Torrey. Bot. Club 82: 419-445.

Sampson, F. B. \& Kaplan, D.R. (1970) Origin and development of the terminal carpel in Pseudowintera traversii. Amer. J. Bot. 57: 1185-1196.

Sattler, R. (1973). Organogenesis of Flowers. A Photographic Text-atlas (University of Toronto Press: Toronto).

Sundberg, M.D. \& Doebley, J.D. (1990) Developmental basis for the origin of polystichy in maize. Maize Genetics Cooperation Newsletter 64: 21-22.

Sundberg, M.D., LaFargue, C. \& Orr, A.R. (1995) Inflorescence development in the 'standard exotic' maize, Argentine popcorn (Poaceae). Amer. J. Bot. 82: 64-74.

Thompson, J.M. (1936a) On the gynoecial apex and the terminal legume of Acacia longifolia and A. suaveolens. Publ. Hartley Bot. Lab. 16: 3-36.

Thompson, J.M. (1936b) Ontogeny of the angiospermic carpel. Nature 137: 458-459.

Troll, W. (1964) Die Infloreszenzen. Typologie und Stellung im Aufbau des Vegetationskorpers, 1. I Deskriptive Morphologie der Infloreszenzen; II Typologie der Infloreszenzen (Gustav Fischer: Jena).

Tucker, S.C. (1959) Ontogeny of the inflorescence and the flower in Drimys winteri var. chilensis. Univ. of California Publications in Botany 30: 257-336.

Tucker, S.C. (1984) Origin of symmetry in flowers. Pp. 351-394, in R.A. White \& W.C. Dickison (eds.), Contemporary Problems in Plant Anatomy (Academic Press: London).

Tucker, S.C. (1987a) Pseudoracemes in papilionoid legumes: their nature, development, and variation. Bot. J. Linn. Soc. 95: 181-206.

Tucker, S.C. (1987b) Floral initiation and development in legumes. Pp. 183-239, in C.H. Stirton (ed.), Advances in Legume Systematics, Part 3 (Royal Botanic Gardens: Kew).

Tucker, S.C. (1988) Loss versus suppression of floral organs. Pp. 69-82 in P. Leins, S.C. Tucker \& P.K. Endress (eds.), Aspects of Floral Development (J. Cramer: Berlin).

Tucker, S.C. (1992) The role of floral developmental in studies of legume evolution. Can. J. Bot. 70: 692-700.

Tucker, S.C. \& Gifford Jr., E.M. (1966) Carpel development in Drimys lanceolata. Amer. J. Bot. 53: $671-678$.

Tucker, S.C. \& Stirton, C.H. (1991) Development of the cymose inflorescence, cupulum and flower of Psoralea pinnata (Leguminosae: Papilionoideae: Psoraleeae). Bot. J. Linn. Soc. 106: 209-227.

Uhl, N.W. (1988) Floral organogenesis in palms. Pp. 25-44 in P. Leins, S.C. Tucker \& P.K. Endress (eds.), Aspects of Floral Development (J. Cramer: Berlin).

Venkata Rao, C. (1971) Proteaceae. Botanical Monograph \#6. (CSIR: New Delhi).

Waddington, C.H. (1962) New Patterns in Genetics and Development (Columbia University Press: New York).

Wardlaw, C.W. (1952) Morphogenesis in Plants (John Wiley \& Sons: New York).

Weber, A. (1973) Die Struktur der parblütigen Partialfloreszenzen der Gesneriaceen und bestimmter Scrophulariaceen. Beiträge zur Biologie der Pflanzen 49: 429-460.

Weberling, F. (1989) The Morphology of Flowers and Inflorescences (Cambridge University Press: Cambridge).

White, J. (1979) The plant as a metapopulation. Ann. Rev. Ecol. Syst. 10: 109-145.

White, J. (1984) Plant metamerism. Pp. 15 47 in R. Dirzo \& J. Sarukhan (eds.), Perspectives on Plant Population Ecology (Sinauer: Sunderland).

Wisniewski, M. \& Bogle, A.L. (1982) The ontogeny of the inflorescence and flower of Liquidambar styraciflua L. (Hamamelidaceae). Amer. J. Bot. 69: 1612-1624.

Wydler, H. (1872) Kleinere Beitragë zur Kenntnis einheimischer Gewächse (Furtsetzung). Mitth. Naturf. Ges. Bern. 1871. S29. 